\title{
Lateral asymmetry in the stability of the visual field
}

Visual targets of low intensity fragment and disappear when fixated in the dark. The present study uses this phenomenon to study the relative perceptual stability of the left and right visual fields. Results indicate a right field superiority.

When visual stimuli are presented tachistoscopically in both the left and right visual fields simultaneously, recognition is generally superior in the left. Heron (1957) attributed this to post-exposural eye movements and Bryden (1960) has shown that the phenomenon is related to the order in which the $\mathrm{S}$ reports the stimuli.

When the visual materials are alphabetic and are presented in either the left or right field, rather than both simultaneously, accuracy is superior in the right field (Mishkin \& Forgays, 1952; Heron, 1957; Bryden \& Rainey, 1963). The same is true, but to a less significant degree, when the stimuli are pictures of known objects. When nonsense geometric forms are presented, there is no difference between the two visual fields (Bryden \& Rainey, 1963).

The superiority of the right field with successive presentation has been related to reading experience (Orbach, 1952) and handedness (Bryden, 1964). The interpretations given for this phenomenon generally fall into one of two categories: a cerebral dominance explanation (Bryden, 1964) or an explanation based on the selective training of the left hemiretinas and efficient organization of the left hemisphere for language material as a result of English reading experience (Mishkin \& Forgays, 1952). Kimura $(1961,1963)$ and Bryden (1964) have suggested an interpretation of cerebral dominance in its relation to language localization to explain the difference in results for the alphabetic and non-alphabetic material.

\section{Method}

The purpose of the present paper is to report on a different, relatively simple technique for measuring dominance in the visual system. It has been observed (McKinney, 1963) that weak luminous stimuli when presented in the dark, fragment and disappear in a perceptually organized fashion. The fragmentations strongly resemble the disappearance of stabilized images (Pritchard, Heron, \& Hebb, 1960) as well as those of prolonged afterimages (Bennet-Clark \& Evans, 1963). The interpretation of these phenomena has been one of a breakdown of cell assemblies, probably in the association cortex (Hebb, 1963).

A series of studies has been conducted, using this technique, to determine the relative stability of the left and right visual fields. In three of the studies a luminous target was used which consisted of two vertical lines, $1 / 2$ in. wide, 8-1/2 in. long and $10 \mathrm{in.} \mathrm{apart.} \mathrm{In}$ the center between the two lines was a circle, 1 in. in diameter. Ss were seated $5 \mathrm{ft}$. from the target in a room which could be completely darkened. At this distance the 11 in. wide target subtends a retinal angle of $11^{\circ} 30^{\prime}$, so that the line on each side impinges $5^{\mathrm{O}_{4}} 45^{\prime}$ from the fovea. Ss were instructed to fixate the circle as soon as the lights were turned off. If either of the two lines disappeared they were to report which line faded first, or if both disappeared simultaneously. After they reported either "Left," "Right," or "Both," for the first trial, the lights were turned on and their response was recorded. The lights were again turned off and the $\mathrm{S}$ was instructed to repeat the same procedure. Each $\mathrm{S}$ was given 10 trials. Between each trial the stimulus card was rotated to control for any differences in brightness between the two lines, although none were ever reported by the Ss or observed by the experimenter.

The first three studies used the luminous apparatus already described, while experiments 4,5 , and 6 made use of a light box as the visual stimulus 2 The target was identical to the earlier used target, although it was now cut from a black stencil and mounted on the Plexiglas surface of the light box, which was first covered with several sheets of sketching paper to reduce the brightness. A variac transformer (set at 80 volts) was connected to the box. The advantage of the light box is its assurance of a constant and uniform brightness. 3 Results and Discussion

A score for each $S$ was obtained by subtracting the number of right field fragmentations from the left field fragmentations. The results of six studies are presented in Table 1.

In all six studies the results indicate greater fragmentation in the left visual field, or, conversely, greater stability of the right field. In the three studies wherein the light box was used, the differences are highly significant. The importance of this finding and the value of the technique, itself, lies in the fact that they refer

Table 1. Mean left field - minus right field disappearances

\begin{tabular}{lllll} 
Exp. & $\begin{array}{l}\text { Source and number } \\
\text { of subjects }\end{array}$ & $\begin{array}{l}\text { Mean left minus } \\
\text { right score }\end{array}$ & $\mathbf{t}$ & $\mathrm{p}$ \\
\hline 1 & Nurses (32 & +.44 & .75 & \\
2 & High School (30) & +.87 & 1.38 & \\
3 & Grade School (20) & +2.00 & 2.00 & .10 \\
4 & High School (58) & +1.50 & 2.94 & .01 \\
5 & College (24) & +2.00 & 2.56 & .02 \\
6 & High School (107) & +1.73 & 3.93 & .001 \\
\hline
\end{tabular}


simply to the perceptual maintenance of a visual target. The use of a tachistoscope involves recognition, and immediate verbal labeling. In the present technique the labels "left" and "right" are already given (although not even required, since a child, for example, may simply point to the side which disappears). Nor is the $S$ given a short-term memory task, as in the case of material presented tachistoscopically to both fields simultaneously where reporting techniques (Bryden, $1960,1963)$ may affect the results. These differences may well provide the basis for the fact that with the tachistoscopic presentation, the right field is superior only for alphabetic material, while the present technique yields differences although the stimuli are not obviously language related.

The fact that the material used in these studies is non-alphabetic does not automatically rule out the possibility that the right field superiority is related to previous reading experience. While earlier studies have tended to emphasize a specialized reading interpretation as contrasted with a general cerebral dominance interpretation it may be that the two are related. That is, the neural pathways leading to and within the left hemisphere may have become more efficient, in general, in maintaining visual perception, through their more constant use involved in looking toward the right side of a page of print. This possibility is currently being investigated with Hebrew reading $S$ s who have learned to read in a right to left order. The effects of handedness, ocular dominance, age and sex on visual laterality are also being studied.

\section{References}

Bennet-Clark, H. C, \& Evan, C. R. Fragmentation of patterned targets when viewed as prolonged after-images. Nature, 1963 , $4899,1215-1216$
Bryden, M. P. Tachistoscopic recognition of non-alphabetic material. Canad. J. Psychol., 1960, 14, 78-85.

Bryden, M. P. Tachistoscopic recognition and verbal dominance. Percept. mot. Skills, 1964, 19, 686.

Bryden, M. P., \& Rainey, C. A. Left-right differences in tachistoscopic recognition. J. exp. Psychol., 1952, 68, 555-562.

Hebb, D. O. The Semiautonomous Process: its nature and nurture. Amer. Psychologist, 1963, 18, 16-27.

Heron, W. Perception as a function of retinal locus and attention. Amer. J. Psychol., 1957, 70, 38-48.

Kimura, D. Some effects of temporal lobe damage on auditory perception. Canad. J. Psychol., 1961, 15, 156-165.

Kimura, D. Right temporal lobe damage. Arch. Neurol., 1963, 8, 264-271.

McKinney, J. P. Disappearance of luminous designs. Science, $1963,140,403-404$.

Mishkin, M. A possible link between interhemispheric integration in monkeys and cerebral dominance in man. In V. B. Mountcastle (Ed.), Interhemispheric relations and cerebral dominance. Baltimore: Johns-Hopkins Press, 1962.

Mishkin, M., \& Forgays, D. G. Word recognition as a function of retinal locus. J. exp. Psychol, 1952, 63, 43-48.

Orbach, J. Retinal locus as a factor in the recognition of visually perceived words. Amer. J. Psychol., 1952, 65, 555-562.

Pritchard, R. M., Heron, W., \& Hebb, D. O. Visual perception approached by the method of stabilized images. Canad.J. Psychol., $1960,14,67-77$.

\section{Notes}

1. Supported by U. S. Public Health Service grant MH 10363-01. 2. "Glow Box" Model No. 12-20 E-2, manufactured by Instruments for Research and Industry. I am indebted to Bruno Kohn, Waterloo University for suggesting the use of a light box rather than the luminous apparatus.

3. The brightness of the two lines was measured with a Macbeth illuminometer at the Ss' viewing distance and approximate eye level. With the power to the light box set at 120 volts, 40 readings were taken for each line at various times during the day to control for possible voltage fluctuations. There was no significant difference between the average brightness of the left line $(.0162$ ft. 1.) and the right line (.0152 ft. 1.). 